\title{
DIVISÃo DE PODERES E REPRESENTAÇÃO EM ROUSSEAU
}

\author{
[DIVISION OF POWERS AND REPRESENTATION IN ROUSSEAU]
}

Resumo: Pretende-se mostrar que as ideias políticas fundamentais de Rousseau parecem sugerir um populismo democrático, pois os cidadãos devem formar uma vontade geral e exercer diretamente a soberania popular, inalienável e indivisível, através do poder legislativo, que elabora leis como atos gerais, as quais devem ser executadas, como atos particulares, pelo príncipe no exercício do poder executivo, o que impossibilitaria a divisão de poderes e a representação. No entanto, usando como método a análise das obras de Rousseau e os comentadores citados nas referências, observa-se que, à medida que ele deduz as consequências destas ideias fundamentais e as pondera por um realismo naturalista, surgem as instituições políticas republicanas, que revelam os limites da soberania popular e a necessidade de um conceito próprio de divisão de poderes e de representação. Neste sentido, conclui-se que o príncipe não somente pode como deve representar o soberano tanto no exercício do poder executivo quanto nas tarefas próprias do soberano, na legislação.

Palavras-ChaVe: Rousseau; Divisão de Poderes; Representação
Aylton Barbieri Durão * Universidade Federal de Santa Catarina, Brasil
Abstract: It is intended to show that Rousseau's fundamental political ideas seem to suggest a democratic populism, as citizens must form a general will and directly exercise popular, inalienable and indivisible sovereignty, through legislative power, which makes laws as general acts, which they must be carried out, as private acts, by the prince in the exercise of executive power, which would make the division of powers and representation impossible. However, using as an method the analysis of the works of Rousseau and the commentators cited in the references, it is observed that, as he deduces the consequences of these fundamental ideas and ponders them for a naturalistic realism, the republican political institutions arise, which reveal the limits of popular sovereignty and the need for a concept of division of powers and representation. In this sense, it is concluded that the prince not only can but must represent the sovereign both in the exercise of executive power and in the sovereign's own tasks, in legislation.

KEYWORDS: Rousseau; Separation of Powers; Representation

\section{§1. INTRODUÇ̃̃̃o ${ }^{1}$}

ranscorridos mais de dois séculos da publicação das obras de Rousseau,
continua repercutindo a concepção de que ele sustentou uma concepção radical de soberania popular e, por isso, negou taxativamente a divisão de poderes e a representação $0^{2}$ "Rousseau condenou a representação em termos peremptórios que se

* Doutorado em filosofia pela Universidad de Valladolid (2003)/Espanha, revalidado pela UFRJ. Professor associado do Departamento de Filosofia da Universidade Federal de Santa Catarina. Email: barbieri@cfh.ufsc.br 
tornaram famosos... Rousseau vê um imenso abismo entre um povo livre fazendo as suas leis e o povo elegendo representantes para fazer as leis por ele" (MANIN, 1).

Esta interpretação foi reforçada recentemente pelo neorrepublicanismo que considerou que o conceito rousseauniano de liberdade como o "autodomínio democrático" se tornou o fundamento para uma corrente política populista, a qual acabou sobreposta e confundida com o ideal republicano de liberdade como nãodominação. Por isso, Pettit afirma que "Rousseau é provavelmente responsável por ter alimentado este enfoque populista" (PETTIT, 30).

No entanto, embora as ideias politicas fundamentais de Rousseau pareçam sugerir uma defesa incondicional do populismo democrático, pois, os cidadãos devem exercer diretamente a soberania popular, inalienável e indivisível, mediante uma vontade geral que não pode ser injusta com ninguém e que não pode errar, acarretando uma censura à divisão de poderes e à representação, pretende-se demonstrar que Rousseau desenvolveu uma teoria política republicana, porque, ao extrair as suas consequências analíticas e depois ponderá-las pelo realismo naturalista, ele introduziu as instituições republicanas que limitaram a soberania popular e produziram dois conceitos de representação, associados com o conceito de divisão de poderes, que podem ser encontrados no Discurso sobre economia política, na "Dedicatória à república de Genebra" do Discurso sobre a desigualdade, mas, principalmente, no Contrato social: (1) o governo não só "pode" como "deve" representar o soberano no exercício do poder executivo por causa dos limites da vontade geral; (2) o governo "pode" e "deve" representar o soberano nos atos próprios da soberania, ou seja, na legislação. Contudo, o seu estilo literário pouco sistemático acabou por encobrir esta "ordem das razões".

\section{§2. A SOBERANiA POPUlaR}

Rousseau apresentou as ideias politicas fundamentais, pacto social, soberania, vontade geral e lei, principalmente no final do Livro I e início do Livro II do Contrato social e introduziu as instituições republicanas, legislador, formas de governo e sistema eleitoral, bem como a sua respectiva modelagem pelo realismo naturalista no final do Livro II e nos Livros III e IV, o que contribuiu para que se consolidasse a miragem do "populismo democrático".

Rousseau mitigou as ideias fundamentais por meio das instituições republicanas, por causa de sua concepção antropológica ambigua, já que desconfiou tanto do povo como das elites. Pois, embora ele considerou o homem bom por natureza, ao contrário de outros republicanos como Maquiavel, que o considerou mal por natureza, a verdade é que ele só é bom na condição de natureza absoluta, quando o chamado "homem original" vivia totalmente isolado dos demais, porém, com o advento da sociabilidade, já com o "homem natural", na fase final do estado de natureza, surgiu a diferenciação entre o seu ser e o seu parecer, que ocasionou todos os males da civilização, que se aprofundaram no estado civil (DI, 102-3). Embora esta relação entre a natureza e a sociabilidade seja mais elaborada no Discurso sobre a desigualdade, ela também transparece no Contrato social: "Tudo o que não é natureza tem os seus inconvenientes e a sociedade civil mais do que todo o resto" (CS III, XV:302).

Deste modo, pode-se descrever uma espécie de dialética entre natureza e sociedade, que se manifesta em três estágios: no estado de natureza, o homem é bom por causa da identidade do homem com a natureza já que ele é um mero animal regido pelo instinto; com o surgimento da sociedade, no final do estado natureza, começa uma contradição entre a natureza e a sociabilidade, fonte das desigualdades, que aumenta no 
estado civil e faz florescer todos os males da civilização; como a humanidade se encontra neste segundo estágio e como é impossível retornar ao estado de natureza, então, para voltar àquela identidade do homem com a natureza e, portanto, restaurar a condição originalmente boa do homem, é necessário edificar instituições politicas que sejam capazes de construir uma república bem-organizada em que os indivíduos permaneçam associados, mas, ao mesmo tempo, totalmente independentes entre si, para tanto, deve-se voltar ao modelo das repúblicas da Antiguidade, especialmente a Lacedemônia e Roma. Constitui uma herança do platonismo de Rousseau, considerar que o futuro significa o retorno ao passado. Contudo, há uma diferença fundamental nestas duas formas de identidade do homem com a natureza, porque, no estado inicial, a identidade provinha da mera animalidade do homem e a sua bondade tinha um significado natural e não moral, porém, neste último estágio, a identidade consiste em uma conciliação possibilitada pelas instituições politicas republicanas entre a sociabilidade e a independência do indivíduo, que conduza à moralização da humanidade.

Por isso, em virtude do pacto social, no qual cada indivíduo entrega a sua pessoa e o seu poder à direção da vontade geral, institui-se um corpo político ou uma pessoa pública denominada "república", a qual se compõe de duas partes ${ }^{3}$, o soberano quando é ativo e o estado quando é passivo, e cujos associados são denominados coletivamente de "povo", mas, individualmente podem assumir a função de cidadãos encarregados da aprovação das leis, enquanto membros do soberano, ou de súditos, que devem obedecêlas, na qualidade de membros do estado (CS I, VI:204-5).

Como, segundo o direito civil, nenhum particular é obrigado a cumprir os compromissos assumidos consigo mesmo, o soberano, como uma pessoa moral, encontra-se na mesma situação de um particular e, portanto, não existe lei que não possa infringir, não sendo obrigado a se sujeitar nem mesmo ao pacto social (CS I, VII:206). Isso parece indicar que o soberano possui poder absoluto, contudo, ao extrair as consequências analiticas das ideias fundamentais ele deduz dois limites da soberania popular: (1) à medida que o soberano constitui um indivíduo com relação a outros soberanos, ele não pode se submeter a outro soberano e nem alienar uma parte de si próprio, porque ele obtém o fundamento do seu ser do próprio contrato social, por isso, violá-lo implicaria aniquilar as suas próprias condições de possibilidade "porque o nada não produz nada" (CS I, VII:206); (2), além disso, como o soberano resulta da associação entre os particulares e só visa o bem comum a todos eles, então, não pode prejudicar a nenhum dos seus membros (CS I, VII:207), mas, como súdito, cada individuo pode agir segundo os seus interesses particulares e, ao se recusar a obedecer a vontade geral, o soberano deve forçá-lo a ser livre (CS I, VII:208). Porque, mediante o pacto social, o indivíduo perde a liberdade natural que consiste no "direito ilimitado a tudo o que deseja e pode conseguir", cujo limite é a força do indivíduo e que lhe permite apenas a posse como primeiro ocupante, mas ganha a liberdade civil por meio da qual se torna senhor de si mesmo uma vez que deve "obedecer apenas a lei que prescreveu para si próprio" fundamentada na vontade geral que transforma a posse na propriedade instituida por um direito positivo (CS I, VIII:209).

Em seguida, Rousseau apresenta, no início do Livro II, as características mais marcantes da soberania que têm sido interpretadas como a confirmação de sua negação da representação e da divisão de poderes e, consequentemente, a adesão ao "populismo democrático", à medida que assevera que a soberania, como o exercício da vontade geral, é inalienável e indivisível.

Como a vontade geral enquadra-se no propósito de compatibilizar a individualidade com a sociabilidade então, ela é formada pela reunião de todos os 
cidadãos, mas estes não podem se comunicar entre si, porque, como toda sociabilidade corrompe, então, a comunicação formaria facções, cada qual com uma vontade geral com relação ao seu grupo, mas particular com respeito à totalidade dos cidadãos, por isso, os cidadãos, enquanto membros do soberano, devem permanecer o mais independentes entre si, isto permitiria que, pela "soma das pequenas diferenças", o interesse comum compartilhado originalmente por cada um pudesse se manifestar. Podese, portanto, explicar a vontade geral a partir da teoria dos conjuntos como o conjunto interseção entre os múltiplos interesses de cada um dos cidadãos, de modo que ela somente expresse o interesse comum a cada um deles deixando de fora os interesses particulares que não são compartilhados por todos.

Consequentemente, a soberania é inalienável porque, se os cidadãos indicassem representantes para deliberar por eles, eles seriam uma parte do povo, então, não formariam a vontade geral, mas apenas a vontade geral dos próprios representantes, que é particular com relação à vontade geral da totalidade do povo; pela mesma razão, a soberania não pode ser dividida entre vários poderes porque cada poder representaria uma vontade particular em relação à vontade geral da totalidade dos cidadãos. Portanto, a vontade é geral porque ela é a expressão dos interesses de cada um dos cidadãos.

Como uma consequência desta generalidade da vontade resultante da necessidade de compatibilizar a individualidade com a sociabilidade surge também uma primeira limitação da vontade geral, pois, a formação da vontade geral não constitui uma verdadeira democracia deliberativa, pois esta exige que os participantes argumentem uns com os outros até chegar a um consenso sobre o tema em debate, mas, com a ausência de uma comunicação recíproca, porque isto levaria ao surgimento de facções e ao risco de que a vontade particular preponderasse sobre a vontade geral, então: (1) a iniciativa legislativa sobre os projetos de lei não competiria aos próprios cidadãos; pois, (2) os cidadãos se limitariam a votar; portanto, (3) a iniciativa legislativa tem que ser aduzida por outros agentes, os magistrados enquanto membros do governo: "Eu teria outras reflexões a fazer sobre o simples direito de votar nos atos de soberania; um direito que nada pode tirar dos cidadãos; e sobre o de opinar, propor, dividir, discutir, que o governo tem sempre grande interesse em deixar apenas para seus membros..." (CS IV, I:312). E, ao tratar dos sufrágios, Rousseau faz outras afirmações de que os cidadãos, nas assembleias populares, se limitam a votar: "quando se propõe uma lei na assembleia do povo... cada um, dando o seu sufrágio, dá a sua opinião sobre ela e, pelo cálculo dos votos, se obtém a declaração da vontade geral" (CS IV, II:315); "resta-me ainda falar sobre o modo de dar e recolher os votos na assembleia do povo" (CS IV, III:319).

Rousseau já havia exposto que compete aos magistrados elaborar a pauta legislativa na "Dedicatória à república de Genebra", ao mostrar que o fato de que qualquer cidadão tinha "o poder de propor novas leis segundo a sua fantasia" acabou fazendo com que a democracia ateniense se perdesse e, para evitar isso, recomendava "que esse direito coubesse apenas aos magistrados" (DI, 11). Assim como teria evitado viver em uma república onde o povo acreditava "poder passar sem magistrados ou lhes deixar apenas uma autoridade precária" e "imprudentemente se tivesse reservado a administração dos negócios civis e a execução de suas próprias leis", "um dos vícios que perderam a república de Atenas" (DI, 12).

Porém, para a vontade ser geral, o objeto da vontade também tem que ser geral, pois, "não se pode formar uma vontade geral sobre um objeto particular" (CS II, VI:229), mas somente sobre os interesses de todos os cidadãos compartilhados em comum. Esse ato da vontade geral que institui um objeto igualmente geral é a lei (CS II, VI:229), logo, a lei reúne a universalidade da vontade e do objeto (CS II, VI:230). Neste sentido, deve-se distinguir um "ato geral", que consiste em aprovar uma lei, pelo 
soberano, comum a todos os cidadãos, de um "ato particular", que considera os aspectos particulares dos indivíduos. Então, o resultado da generalidade da lei é que ela deixa para o arbítrio do indivíduo muito mais do que lhe submete, pois, não se pode legislar sobre aquilo que é particular. Da limitação da vontade geral aos objetos gerais, Rousseau extrai analiticamente duas outras limitações, pois tudo o que não for um ato geral, não pode ser objeto de legislação:

(1) a vontade geral não pode onerar mais um indivíduo do que a outro, pois como o objeto das leis é sempre geral, elas devem tratar os súditos coletivamente e as suas ações abstratamente, sem considerar um indivíduo concreto ou uma ação particular:

Para esclarecer essa questão, observaremos que, de acordo com o pacto social, o soberano somente podendo agir por vontades comuns e gerais, seus atos devem ter apenas objetos gerais e comuns; Daí resulta que um indivíduo não pode ser lesado diretamente pelo soberano sem que todos o sejam também, mas isto não pode acontecer, visto que seria desejar fazer o mal a si próprio (E, 409).

De fato, Rousseau afirma que a vontade geral pode aprovar as leis sobre a guerra ou a paz, mas não pode decretar a guerra ou a paz, porque estes são atos particulares (CS II, II:216). A vontade geral pode estabelecer privilégios, mas não pode indicar os beneficiários (CS II, VI:229). A vontade geral também poderá determinar a forma de governo e o método de escolha dos magistrados, mas não poderá nominar ou mesmo votar nos candidatos durante a eleição, pois a escolha dos candidatos também constitui um ato particular (CS II, VI:229-230). A vontade geral também pode aprovar a legislação civil e penal, mas não poderá decidir nem como executá-la em um caso determinado, nem como aplicá-la em julgamento concreto, porque estes também são atos particulares.

Vê-se por aí que o poder soberano, todo absoluto, todo sagrado, todo inviolável como é, não passa nem pode passar além dos limites das convenções gerais, e que todo homem pode dispor plenamente dos seus bens e da liberdade que lhe foi deixada por essas convenções (CS II, IV:224).

(2) A transição do estado de natureza para o estado social, da lei natural para a legislação aprovada pela vontade geral, tem que ser vantajosa para o indivíduo (E, 409), ainda que isto permita justificar o direito do soberano de convocar o súdito para a guerra, porque, no estado de natureza, o indivíduo também precisava lutar contra os outros, mas no estado civil, esta tarefa somente acometeria alguns, enquanto a maioria somente teria que pagá-la com os seus impostos. O soberano também pode aprovar a pena de morte, pois, assim como a lei natural permite que um indivíduo arrisque a sua vida se for para salvá-la, como ocorre quando ele se atira de um prédio em chamas, porque troca uma morte certa por uma duvidosa, a instituição da pena de morte coloca a vida do indivíduo em risco, caso seja condenado, mas o faz com a intenção de evitar se tornar a vítima de um crime (CS II, V:226).

Como a corrupção humana advém da contradição entre a natureza e a sociabilidade que atingiu o seu auge justamente com a civilização, não se pode esperar que os homens modernos instaurem uma república bem-organizada, mas, ao contrário, deve-se esperar que as leis da república disciplinem o comportamento humano. Por isso, ele concorda com Montesquieu: "no nascimento das sociedades...são os chefes das repúblicas que fundam a instituição e, depois, é a instituição que forma os chefes da república" (CS I, VII:232).

Portanto, inspirado no conceito do "fondatore d'una Republica" de Maquiavel (CS II, III:219), Rousseau introduziu a primeira das grandes instituições republicanas capazes de concretizar as ideias fundamentais: o legislador. Rousseau admirava 
Maquiavel a ponto de considerar que $O$ príncipe, "o livro dos republicanos", não foi escrito para elogiar os reis, mas para dar grandes lições ao povo (CS III, IV:272), ao desnudar os descalabros da monarquia. Seguindo o filósofo italiano, ele cita o exemplo da história, pois as grandes repúblicas da Antiguidade tiveram legisladores que elaboraram a sua constituição: Licurgo de Esparta, Sólon de Atenas, Numa e Sérvio de Roma (CS, II, III:220). O legislador deveria instituir a república, mas as suas funções não deveriam entrar na sua constituição, pois ele não ocuparia cargo de soberania ou de magistratura no governo, por isso, as pólis gregas e as repúblicas italianas do Renascimento costumavam incumbir estrangeiros desta missão (CS II, VII:233-4).

Entre estes legisladores, Rousseau incluiu Calvino, um estrangeiro 4 que elaborou a constituição de sua amada Genebra, e, a este fato, ele atribuiu as grandes virtudes de suas instituições (CS II, VII:234).

O próprio Rousseau assumiu o papel de legislador quando foi convidado para elaborar a constituição da Córsega depois que escreveu que esta ilha era o último pais da Europa capaz de aceitar uma legislação e, por isso, ainda surpreenderia a Europa (CS II, X:246), o que resultou em seu livro Projeto de constituição para a Córsega, de 1764, e, posteriormente, quando foi convidado para reformar as instituições políticas da Polônia em Considerações sobre o governo da Polônia, de 1771.

Embora Rousseau afirme que não podem existir leis obrigatórias para o soberano, a figura do legislador acarreta uma notável restrição do papel da soberania popular e da vontade geral, pois, quando os cidadãos se reúnem para exercer a soberania já encontram a constituição previamente estabelecida, a qual define (1) a forma da cidadania, (2) delineia as instituições e os procedimentos nos quais os cidadãos devem exercê-la e, também, (3) as leis mais fundamentais do estado.

O próprio Rousseau, como legislador, no Projeto de constituição da Córsega estabeleceu uma definição bastante precisa e restritiva de cidadão: o cidadão "deve ter 20 anos ou mais" (PC, 31), "ser casado ou viúvo, ter pelo menos dois filhos vivos, casa para morar e propriedade da terra suficiente para viver dela" (PC, 32). Portanto, as duas condições fundamentais para a cidadania são a família e a propriedade. Ademais, quando apresentou as instituições do governo revelou um determinismo geográfico, já que a forma de governo deve ser decidida com base no clima e no relevo, e considerou que nem toda forma de governo é adequada para qualquer país.

\section{§3. GOVERNO}

Rousseau apresenta uma terceira parte da república que ocupa um espaço intermediário entre o soberano e o estado, o príncipe, cuja função é o governo, cujos membros desempenham o papel de magistrados que executam e aplicam as leis aprovadas pelos cidadãos, as quais devem ser seguidas pelos súditos (E, 413). Portanto, como órgão intermediário, ele é subordinado ao soberano e deve simplesmente transmitir as suas ordens para o povo.

É absolutamente apenas uma comissão, um emprego no qual, como simples funcionários do soberano, eles exercem, em seu nome, o poder que ele lhes fez depositários, e que ele pode limitar, modificar e retomar sempre que quiser; a alienação de tal direito é incompativel com a natureza do corpo social e contrária ao objetivo da associação (CS III, I:253-4).

Evidentemente que estas observações estão de acordo com a afirmação de que a soberania é indivisível e parecem confirmar que não há divisão de poderes na república. Não obstante, ele apresenta três razões (duas analíticas e uma política) pelas 
quais é absolutamente necessário separar o soberano, o poder legislativo, do governo, o poder executivo:

(1) Uma vez que o soberano se ocupa unicamente da vontade geral e, por isso, a universalidade dos cidadãos só pode aprovar leis a partir de objetos gerais, o que as torna atos gerais, então, é analiticamente necessário separá-lo do governo, cujos atos particulares são decretos que devem tratar dos objetos particulares $(\mathrm{E}, 411)$. Por isso, o soberano desempenha unicamente o poder legislativo, enquanto o governo se encarrega exclusivamente do poder executivo.

Vimos que o poder legislativo pertence ao povo, e só pode pertencer a ele. É fácil ver, pelo contrário, pelos princípios estabelecidos anteriormente, que o poder executivo não pode pertencer à generalidade como legislador ou soberano, porque esse poder consiste apenas em atos particulares que não estão dentro do alcance da lei, nem, por conseguinte, pelo Soberano, cujos atos só podem ser leis (CS III, $\mathrm{I}: 253)$.

E, neste mesmo sentido:

O poder legislativo, uma vez bem estabelecido, trata-se de estabelecer igualmente o poder executivo; porque este último, que só opera através de atos particulares, não sendo da essência do outro, está naturalmente dele separado. Se fosse possível que o soberano, considerado como tal, tivesse o poder executivo, o direito e o fato seriam de tal modo confundidos que não mais se saberia o que é lei e o que não o é (CS III, XVI:303-4).

(2) Rousseau também distingue analiticamente o soberano do governo, ao retomar a analogia entre o corpo do indivíduo e o estado como corpo político, pois, assim como o indivíduo somente pode agir mediante uma combinação de vontade e força, o corpo político necessita da combinação da vontade geral do soberano, que detém apenas o poder legislativo, com a força do governo, que dispõe exclusivamente do poder executivo. E, fundamentando-se na ideia de que o governo ocupa um lugar intermediário entre o soberano e o estado, ele expressa esta relação em termos matemáticos de tal modo que o equilíbrio público exige uma proporção segundo a qual o soberano está para o governo, assim como o governo está para o estado, o que ocorre quando o soberano transmite ao governo as ordens que ele deve dar ao povo. Contudo, uma alteração nesta proporção, que ocorre quando o soberano quer governar, o governo quer legislar ou o povo se recusa a obedecer, afeta de tal forma o equilíbrio público que o estado descamba ou para o despotismo ou para a anarquia (CS III, I:254; E, 413-4).

Ademais, a força do governo se subdivide em dois tipos: a força real ou absoluta é a força que o governo tem que exercer sobre os membros do estado, os súditos, enquanto a força relativa constitui a força que o governo exerce sobre os seus próprios membros, os magistrados. Rousseau considera que estes dois tipos de força apresentam muitas variações possíveis resultando em distintas combinações entre elas dependendo das circunstâncias empíricas de cada estado, bem como que esta relação entre a força absoluta e a força relativa constitui um princípio para explicar a forma de governo adequada para cada estado (CS III, II:256).

Como exemplo, ele cita o caso em que há um incremento na população. Com o aumento da população há um acréscimo no número de cidadãos, o que resulta em uma redução da importância de cada um deles na formação da vontade geral, contudo, como súdito, ele continuará contando como um indivíduo, que terá que suportar toda a carga da legislação, então, o incremento na população implica um aumento da força real ou absoluta exercida sobre cada súdito, o que provoca uma perda de liberdade (CS III, $\mathrm{I}: 255)$. 
No entanto, deve-se fazer duas observações sobre este argumento:

a) A tese da perda da liberdade por causa do aumento da coerção proveniente do incremento da população é contraditória. Afinal, se o número de cidadãos que participa das assembleias populares é pequeno, então, existe uma possibilidade maior de que a vontade particular prepondere sobre o interesse comum e o resultado se afaste da vontade geral, porém, quando aumenta o número de cidadãos, isto propicia o incremento da anulação recíproca das pequenas diferenças, garantindo que a lei aprovada corresponda à vontade geral. Mas, se a lei é o resultado da vontade geral, então, a coerção da lei consiste em obrigar o súdito a obedecer a sua própria vontade legisladora, o que deveria resultar em um aumento da sua liberdade civil, conforme ele afirmou anteriormente: "caso se recuse a obedecer à vontade geral, será coagido por todo o corpo: mas isto não significa outra coisa a não ser que ele será forçado a ser livre" (CS I, VII:208).

O "truque de prestidigitação filosófico" realizado por Rousseau consiste em, subrepticiamente, substituir a liberdade civil pela liberdade natural, que é o "direito ilimitado a tudo o que deseja e pode conseguir", cuja extensão é a força do indivíduo, por isso, o aumento da coerção representa uma perda da liberdade, mas a liberdade natural não poderia ter sido aduzida neste contexto porque, pelo pacto social, o indivíduo renunciou à ela em favor da liberdade civil (CS I, VIII:209).

b) Também não há motivo para esperar que o aumento da população implique um incremento da coerção do governo, isto só seria necessário se os súditos reduzissem a sua obediência à lei, portanto, a fórmula matemática segundo a qual o equilibrio público depende de que a proporção entre o soberano e o governo seja igual à proporção entre o governo e o estado, de fato, apenas mistifica a verdadeira concepção de Rousseau, que não é matemática, mas política, segundo a qual a virtude dos súditos depende da homogeneidade de costumes, o que somente pode ser conseguido em estados pequenos, mas, com o crescimento da população, os súditos passam a seguir valores muito heterogêneos o que faz com que as leis percam o seu substrato nos costumes e, por isso, a virtude dos súditos tenha que ser compensada pelo aumento da coerção da lei (CS III, I:255-6; E, 414-5).

Depois destas duas observações cabe retornar aos argumentos de Rousseau. Ele afirma que o aumento da população também exige o incremento do governo, pois este terá mais atividades. Porém isto tem como consequência que o governo deve exercer mais força relativa também sobre os seus próprios membros, contudo, quanto mais força relativa exerce sobre os magistrados, menos força real ou absoluta resta ao governo para empregar sobre os súditos. Logo, a força relativa é inversamente proporcional à força real ou absoluta (CS III, II: 262).

Contudo, o aumento da população torna necessário aumentar tanto a força real ou absoluta quanto a força relativa. Para resolver esta aparente contradição, Rousseau argumenta que a força é maior quanto mais concentrada for, pois a vontade individual é proporcionalmente mais forte do que a vontade do corpo de magistrados, que, por sua vez, é proporcionalmente maior do que a da vontade geral da totalidade dos cidadãos. Portanto, deve-se promover uma diferenciação no conjunto dos magistrados, dividindoos em simples magistrados, que exercem funções administrativas destituídas de poder, e magistrados superiores, que dispõe efetivamente de poder político. Consequentemente, o aumento da população deve implicar na redução do número de magistrados superiores, os quais, ao concentrar mais poder, podem exercer mais força relativa sobre os simples magistrados e mais força real ou absoluta sobre os súditos (E, 415). Logo, a democracia convém aos estados pequenos, a aristocracia aos estados medianos e a monarquia aos estados grandes (CS III, III:264; E, 418). 
De fato, Rousseau observa que não é qualquer tipo de governo que convém a qualquer país, justamente porque as condições geográficas, como a extensão territorial e populacional, o clima ou relevo determinam a forma de governo mais adequada para cada país, por isso, o legislador deveria tê-las em conta na hora de elaborar a constituição (CS III, VIII:281). Mas isto significa que estas condições naturais representam outros limites adicionais à soberania popular.

(3) A teoria da divisão de poderes proposta por Montesquieu em $O$ espírito das leis, se baseava em uma teoria da modernidade, segundo a qual os modernos são diferentes dos antigos, porque, enquanto os antigos possuíam virtudes cidadãs capazes de participar ativamente do governo da pólis, os modernos estão mais preocupados com as virtudes privadas, menosprezando o civismo. Como o cidadão, refluiu para a esfera privada, Montesquieu lamenta que não se possa preservar o modelo político republicano da Antiguidade e, demonstrando uma admiração pelo parlamentarismo britânico, considera que a única alternativa para evitar o despotismo, comum nos estados modernos, seria elaborar uma divisão em três poderes, o legislativo, o executivo e o judiciário, independentes e harmônicos, que instituiriam uma série de pesos e contrapesos um em relação ao outro de modo a evitar o poder absoluto.

No entanto, o republicanismo clássico defendia outra teoria da divisão de poderes oriunda de Aristóteles. Na Política, Aristóteles propôs a divisão em três poderes (1297b1298a) para acomodar as três classes politicas permanentes, a realeza, a nobreza e o povo, as quais originam três formas puras de governo, monarquia, aristocracia e democracia, com suas respectivas formas corrompidas. Como Aristóteles defendia um republicanismo popular, ele afastou o elemento monárquico e imaginou a república como o governo misto da democracia com a aristocracia (1293b). Neste sentido, o legislativo e o judiciário deveriam ser exercidos diretamente pelo povo e organizados mediante o sorteio, enquanto o executivo deveria ser exercido por uma aristocracia cujos magistrados fossem escolhidos por eleição (1294b).

Maquiavel mostrou que este modelo de divisão de poderes tinha duas vantagens: como tanto as formas puras quanto as impuras são instáveis porque as outras classes políticas tramam para tomar o poder, então, a república tem que ser uma forma de governo misto, que lança mão de diferentes instituições políticas para acomodar cada uma destas classes, o que explica a sua grande estabilidade (MACHIAVELLI, 13).

Portanto, os cidadãos devem exercer a soberania popular, mas, ao mesmo tempo, deve-se evitar os excessos da democracia, pois o povo delibera e julga apaixonadamente, por isso, a soberania popular deve ser ponderada tanto pelas leis quanto por instituições aristocráticas e/ou monárquicas, contudo, também deve-se impedir que a maior capacidade de decisão destas instituições possa levar à formação de uma elite política que sobrepuje o papel do povo e da democracia.

Embora $O$ espírito das leis de Montesquieu tenha sido publicado pouco antes das principais obras de Rousseau, o genebrino descarta este modelo e reconstrói, a sua maneira, a teoria republicana clássica, por isso, ele aceitou que a divisão de poderes visa acomodar as classes políticas do estado e isto explica também a sua concepção sobre as formas de governo.

Segundo Rousseau o povo, enquanto soberano, dispõe do poder legislativo, portanto, restaria apenas determinar qual das três classes políticas deve ocupar o governo, o poder executivo. Isto implica que ele teve que introduzir uma modificação no conceito tradicional de governo misto. Porque, na concepção republicana tradicional, o conceito de governo misto significa que as classes politicas, a realeza, a nobreza ou povo ocupam alternadamente um ou dois dos três poderes, mas, como, para o genebrino, o governo se refere unicamente ao poder executivo, então, o governo misto surge apenas 
se o poder executivo for dividido entre estas classes (CS III, VII:278). Por isso, Rousseau não considera que o seu modelo de república, em que uma classe ocupa o poder legislativo e outra o poder executivo, constitua uma forma de governo misto, como ocorre no republicanismo tradicional, mas, do mesmo modo que o republicanismo tradicional, ele também considera que classes políticas diferentes devem ocupar poderes diferentes na república.

Ademais, não são razões de estabilidade que norteiam a divisão de poderes entre as classes políticas diferentes, como pensou Maquiavel, mas o que ele pretende é evitar a confusão entre a vontade geral e a vontade particular, que surgiria se uma mesma classe política ocupasse os dois poderes simultaneamente. Caso isto ocorresse, ao se dedicar tanto aos atos gerais que constituem as leis no poder legislativo, quanto aos atos particulares que elaboram os decretos no poder executivo, seria muito difícil separar as duas funções e, provavelmente, haveria uma contaminação da vontade geral pela vontade particular na promulgação das leis (CS III, IV:265) e isto constitui um mal maior do que a possibilidade de abuso do poder político.

Por isso, pode parecer que a democracia seja a melhor forma de governo, pois, como o povo já ocupa o poder legislativo, aquele que elabora as leis deveria saber melhor o modo de executá-las. Mas, na verdade, todas as menções que Rousseau faz da democracia ou à Atenas ${ }^{5}$ são depreciativas: "um dos vícios que levaram a perder a República de Atenas" e do qual Rousseau desejava fugir consistia no fato de que ela era "necessariamente mal governada" porque "o povo, acreditando passar sem magistrados, ou deixá-los apenas uma autoridade precária, guardava imprudentemente para si a administração de assuntos civis e a execução de suas próprias leis" (DI, 12); "Atenas não era de fato uma democracia, mas uma aristocracia muito tirânica, governada por sábios e oradores" (EP, 369); "jamais existiu uma verdadeira democracia e jamais existirá, pois é contra a ordem natural que o grande número governe e o pequeno seja governado" (CS III, IV:265-6). E, o argumento do Contrato social consiste em mostrar justamente que se o povo ocupar tanto o poder legislativo quanto o poder executivo aumentam as chances de que a vontade particular contamine a vontade geral. Por isso, "se houvesse um povo de deuses, ele seria governado democraticamente. Um governo tão perfeito não convém aos homens" (CS III, IV:267).

Rousseau também considera que a monarquia não é a melhor forma de governo (no plano normativo), porque, como na monarquia prevalece a vontade de uma única pessoa, existe uma grande possibilidade de que a vontade particular do governante usurpe a vontade geral do soberano (CS III, VI:271). No entanto, razões analíticas o levam a aceitar que a monarquia é a melhor forma de governo quando o estado é grande ou populoso porque necessita de um governo mais forte e o governo é tanto mais forte quanto mais concentrado nas mãos de menos magistrados superiores, bem como o seu realismo naturalista o leva a considerar que a monarquia é a melhor forma de governo em regiões com clima tropical.

Por fim, a aristocracia se divide em três tipos, a natural, formada pelos povos que saem do estado de natureza, em que os membros mais velhos da família ocupam o poder do estado, a aristocracia eletiva, que é a melhor forma de governo (LM, 293-4), e a aristocracia hereditária, que é a pior. $\mathrm{Na}$ aristocracia eletiva, "o príncipe elege o príncipe" (CS IV, III:318) porque o soberano não pode nem nominar, nem votar em candidatos, uma vez que estes constituem atos particulares, o que somente pode ser exercido pelo próprio governo. Portanto, no plano normativo, a república para Rousseau mescla a democracia, exercida pelo povo no poder legislativo, com a aristocracia, exercida por uma elite eleita no poder executivo.

Destas observações, podem-se extrair as seguintes conclusões: (a) devido à 
separação dos atos gerais dos atos particulares, que somente podem ser executados pelo principe, a afirmação de que o governo não passa de um funcionário do soberano constitui pura retórica já que compete ao governo funções indispensáveis que não podem ser executadas pelo soberano, como a iniciativa legislativa, a declaração da guerra e da paz, a execução de todos os programas políticos, econômicos e sociais, a aplicação da justiça e a realização de eleições, logo, se o poder executivo dispõe de uma competência específica que não pode ser realizada por outro poder, então, ele constitui um poder independente e se deve aceitar que há uma divisão de poderes; (b) como os cidadãos se limitam a votar nas assembleias populares e não pode haver comunicação entre eles no processo de formação da vontade geral, então, a iniciativa legislativa cabe ao príncipe e, por isso, resulta parcialmente retórica a afirmação de que o soberano pode modificar ou destituir o governo quando lhe aprouver, pois caberia ao próprio governo a iniciativa legislativa de propor a sua destituição ou modificação e, pertenceria ao soberano apenas a faculdade de aprovar ou recusar estas ações com o seu voto. Rousseau percebeu a limitação de sua teoria e, para tentar evitá-la, introduziu três cláusulas ad hoc: as assembleias populares devem ser frequentes e não depender de convocação formal do governo, além disso, no início de cada assembleia deveriam ser feitas obrigatoriamente duas consultas ao soberano, se ele deseja conservar a forma de governo vigente e se quer manter os atuais magistrados (CS III, XVIII:308-9); (c) diferentemente do que imagina a interpretação tradicional, a indivisibilidade da soberania é compativel com a divisão de poderes entre o soberano e o príncipe, entre o poder legislativo e o poder executivo, porque a soberania continua indivisível, uma vez que somente ao soberano compete a aprovação das leis, que são atos gerais, mediante a formação da vontade geral, enquanto o governo se ocupa apenas dos atos particulares, sem se imiscuir nos atos da soberania, por isso, a divisão de poderes não refuta, mas visa justamente garantir a indivisibilidade da soberania; (d) além do mais, os argumentos elencados anteriormente explicam também as razões porque, embora Montesquieu tenha publicado, em 1748, pouco antes dos primeiros trabalhos de Rousseau, a sua teoria dos três poderes, o genebrino continuou sustentando a divisão em dois poderes, o legislativo e o executivo. Os dois primeiros argumentos analíticos mostram que é necessário distinguir os atos gerais e os atos particulares, bem como a vontade e a força, portanto, torna-se necessário existir apenas dois poderes, o legislativo deve se encarregar da aprovação dos atos gerais mediante a formação da vontade e o executivo deve impingir a força para a execução dos atos particulares. Do mesmo modo, o argumento político, ao afastar tanto a democracia, quanto a monarquia, mostra que a república deve incorporar as duas classes políticas do estado, neste sentido o soberano deve ser ocupado pelo povo e o governo, pela aristocracia, portanto, são necessários unicamente dois poderes para acomodar as classes políticas que devem compor uma república bem-organizada; (e) por fim, se a democracia convém aos estados pequenos, a aristocracia aos estados medianos e a monarquia aos estados grandes, mas Rousseau rejeita a democracia porque pode gerar uma confusão da vontade geral com a vontade particular uma vez que o povo ao mesmo tempo legisla e governa, assim como a monarquia, porque a vontade particular do rei, que ocupa o governo, tende a prevalecer sobre a vontade geral do povo e, por isso, prefere a aristocracia eletiva como a melhor forma de governo, então, a sua amada cidade-estado de Genebra não pode ser o modelo de república bem-organizada, porque o melhor governo, a aristocracia, corresponde aos estados medianos, por isso, tanto no Discurso sobre economia política, como na "Dedicatória à república de Genebra", mas principalmente no Contrato social, o paradigma é a República de Roma. 


\section{§4. REPRESENTAÇÃo}

Aparentemente, a inalienabilidade da soberania torna impossível a representação, o que parece ser confirmado com a queixa de Rousseau sobre a falta de virtudes cívicas dos cidadãos de sua época, os quais "se é preciso ir à assembleia, eles nomeiam os deputados e continuam em casa. À força de dinheiro e preguiça, eles dispõem de soldados para servir a pátria e de representantes para vendê-la" (CS III, XV:299). Por outro lado, Rousseau parece indicar a possibilidade de alguma forma de representação, pois, justamente no parágrafo em que mais incisivamente nega a representação por causa da inalienabilidade da soberania, admite a existência de deputados do povo:

A soberania não pode ser representada, pela mesma razão que não pode ser alienada; ela consiste essencialmente na vontade geral, e a vontade não se representa; ou é a mesma ou é outra; não há nisso meio termo. Os deputados do povo não são nem podem ser os seus representantes; são apenas seus comissários, nada podendo concluir definitivamente. Todas as leis que o povo pessoalmente não tenha ratificado são nulas; não são leis (CS III, XV:300-1).

Logo, este parágrafo sugere que a forma de representação que Rousseau parece rejeitar é o chamado mandato não-imperativo segundo o qual os deputados, uma vez eleitos, tem independência em relação aos seus eleitores. Isto é corroborado por sua crítica ao parlamentarismo britânico, elogiado por Montesquieu, pois considera que o povo britânico somente seria livre durante as eleições, mas seria escravo durante todo o mandato dos deputados que eles elegeram (CS III, XV:301).

Portanto, a inalienabilidade da soberania seria preservada pelos deputados do povo, desde que fossem simples comissários e não pudessem tomar decisões definitivas sem a sua ratificação pessoal pelo povo, ou seja, se os deputados tivessem um mandato imperativo. Porém, o mandato imperativo é negado no Contrato social. De fato, ele o rejeita na versão não publicada do Contrato social, o chamado "Manuscrito de Genebra":

Além disso, uma regra fundamental para toda sociedade bem constituída e governada de forma legítima deve ser a de que todos os seus membros possam ser reunidos facilmente toda vez que isto for necessário, pois veremos mais adiante que as assembleias com representantes delegados nem podem representar bem toda a nação nem receber dela o poder suficiente para fazer as leis em seu nome, soberanamente (CSFR II, III:144).

O problema é que "a ideia dos representantes é moderna" (CS III, XV:301), pois "nas antigas repúblicas e mesmo nas monarquias, o povo jamais teve representantes" (CS III, XV:301), e Rousseau pretende construir o seu modelo de república bem-organizada justamente a partir de uma reconstrução normativa das instituições republicanas da Antiguidade, notadamente de Roma.

Logo, a inalienabilidade da soberania popular impede a representação legislativa inclusive por meio de mandato imperativo, porém, isto implica que o termo "deputados do povo" não pode ser interpretado como "representante legislativo", mas como sinônimo de "magistrados do governo". Por este motivo, ele equipara estes "deputados do povo" aos tribunos da plebe, os quais, por mais sagrados que fossem considerados, deviam dispor apenas da iniciativa legislativa (função do governo), mas não podiam decidir nada definitivamente, pois todos os seus projetos precisavam ser ratificados pessoalmente pelo povo nas Assembleias da Plebe sob pena de se tornarem nulos (CS III, XV:301-2).

Consequentemente, embora o soberano não possa ser representado no poder 
legislativo, em virtude da inalienabilidade da soberania, Rousseau desenvolve um outro conceito de representação a medida que considera que o soberano, não somente "pode" como "deve" ser representado pelo governo no poder executivo, com a finalidade de evitar a confusão da vontade geral com a vontade particular:

Para explicar, entretanto, como os tribunos as vezes representavam o povo, basta conceber como o governo representa o soberano. Sendo a lei a declaração da vontade geral, fica claro que no poder legislativo não pode o povo ser representado; mas pode e deve sê-lo no poder executivo, que é somente a força aplicada à lei (CS III, XV:301-2).

Contudo, embora fique explícito que o conceito rousseauniano de representação seja exclusivamente associado ao governo no Contrato social e no Emílio (ambas de 1762), vários autores (MASTERS, 411-413; DERATHÉ, 79-80; FRALIN, 1-11; MILLER, 128; MANIN, 165) passaram a considerar que, nas obras posteriores, Cartas escritas da montanha (1763-4), Projeto de constituição para a Córsega (1767) e, principalmente, Considerações sobre o governo da Polônia (1772), aparecem indicações da representação legislativa, o que poderia ser explicado ou como uma concessão pragmática ao realismo político ou, inclusive, como resultado de uma evolução normativa no pensamento de Rousseau. Contudo, esta passagem do Projeto de constituição para a Córsega demonstra que o termo "deputados do povo" deve ser entendido simplesmente como sinônimo de "magistrados", ou seja, membro do poder executivo, e, portanto, que o conceito de representação continua significando que o governo representa o soberano ou o poder executivo representa o poder legislativo:

É verdade que existe em sua aplicação algumas modificações a serem feitas devido ao tamanho da ilha; porque um governo puramente democrático combina com uma cidade pequena, em vez de uma nação. Não se poderia reunir todo o povo de um país como este em uma cidade e quando a autoridade suprema é confiada aos deputados, o governo muda e se torna aristocrático. Aquele que combina com a Córsega é um Governo misto, onde o povo se reúne apenas em partes e onde os depositários de seu poder são frequentemente renovados (PC, 12).

Ademais, o sentido da afirmação de que o príncipe "pode" e "deve" representar o soberano não se resume ao exercício do governo ou do poder executivo, mas, Rousseau assevera explicitamente, nos Discursos sobre economia política, que o príncipe também "pode" e "deve" representar o soberano no exercício da atividade específica do soberano, ou seja, na formação da vontade geral e, portanto, no exercício do poder legislativo, o que significa que o corpo de magistrados que compõe o príncipe "pode e deve" elaborar as leis:

Como, me diriam, se reconhecerá a vontade geral nos casos em que ela não foi expressa? Dever-se-á reunir toda a nação para cada acontecimento imprevisto? Dever-se-ia evitar reuni-la, pois não se tem certeza de que a sua decisão seja a expressão da vontade geral; ademais, este meio é impraticável para um povo grande e raramente torna-se necessário quando o governo é bem-intencionado: porque os chefes sabem muito bem que a vontade geral está sempre do lado mais favorável ao interesse público, isto é, do lado mais equitativo; de modo que bastará ser justo para garantir seguir a vontade geral. Normalmente, quando se choca abertamente contra ela, ela se deixa perceber apesar do terrível freio da autoridade pública. (EP I:375)

Nesta passagem, Rousseau considera que o príncipe "pode" e "deve" representar o soberano na elaboração de leis, mas apenas nos casos em que é preciso tomar uma decisão na ausência da lei e que a sua ação legislativa é limitada a uma 
situação excepcional, em que se evitaria reunir a nação em virtude de um "acontecimento imprevisto", contudo, o príncipe não poderia exercer a função legislativa nos casos em que o soberano já se pronunciou através das leis vigentes. Ele apresenta dois argumentos empíricos e um normativo para justificar esta ação legislativa supletória do principe: (1) existem circunstâncias que impedem a reunião dos cidadãos, como as dimensões territoriais e populacionais do estado; (2) e também porque não há garantia de que a reunião dos cidadãos expresse a vontade geral; (3) por outro lado, o príncipe pode expressar a vontade geral melhor do que os próprios cidadãos. Por isso, o príncipe pode prescindir do procedimento descrito para a elaboração da lei pela vontade geral (o qual exige a reunião dos cidadãos sem comunicação recíproca que promova a neutralização das pequenas diferenças e permita aflorar os seus interesses comuns), uma vez que, para expressá-la, basta que tome a decisão mais "justa", "equitativa" e "favorável ao interesse público" e pode-se perceber facilmente quando o governo viola a vontade geral, por mais que ele lance mão do poder de repressão.

Evidentemente que se poderia retrucar que esta afirmação encontrada nos Discursos sobre economia política (1754) corresponde a uma formulação mais antiga do pensamento de Rousseau o qual teria evoluído para uma versão mais forte da soberania em sua obra mais importante, o Contrato social (1762), em que expressa claramente a sua inalienabilidade e indivisibilidade, embora já se tenha mostrado as restrições da soberania popular, inclusive nesta última obra. Contudo, precisamente no capítulo em que Rousseau assinala de forma mais contundente a inalienabilidade da soberania, o Capítulo I, Livro II do Contrato social, intitulado "A soberania é inalienável", reafirma, no último parágrafo, a ideia de que o príncipe pode formar a vontade geral sem o concurso do soberano: "Isso não quer dizer que as ordens dos chefes não possam ser consideradas como vontades gerais, desde que o soberano, livre para opor-se a elas, não o faça. Neste caso, deve-se presumir o consentimento do povo a partir do seu silêncio universal (CS II, I:215)".

Embora a argumentação de Rousseau neste parágrafo tenha sido menos detalhada do que nos Discursos sobre economia política, agora ele aduz uma nova e elucidativa justificativa para que o príncipe expresse a vontade geral no lugar do soberano: a ausência de protestos populares demonstra o consentimento implícito do soberano às leis elaboradas pelo governo. Além disso, não consta mais a limitação de que o príncipe deveria representar o soberano apenas diante de um "acontecimento imprevisto", o que parece indicar que deve fazê-lo também em situações ordinárias. Estas observações permitem sacar a conclusão de que os cidadãos consideram que as decisões do governo somente não correspondem à vontade geral quando o povo recorre às manifestações e protestos. Entretanto, dada a sua própria concepção de que a vontade é mais ativa quanto mais é concentrada, o que significa que a vontade do indivíduo é mais ativa do que a vontade de corpo dos magistrados que compõem o príncipe a qual, por sua vez, é a mais ativa do que a vontade geral do soberano, isso implica que, na prática, a maior atividade da vontade dos magistrados resultaria que, ordinariamente, a legislação acabaria sendo elaborada pelo príncipe e que o papel da soberania se reduziria a expressar a vontade geral nas manifestações populares de protesto contra as decisões do poder executivo e, apenas extraordinariamente, a iniciativa legislativa, ainda que informal, caberia aos próprios cidadãos.

\section{REFERÊNCIAS}

ARISTOTLE. Politics - A Treatise on Government. The Project Gutenberg EBook of Politics, by Aristotle. 
BACHOFEN, Blaise. La condition de la liberté. Rousseau, critique des raisons politiques. Paris: Payot, 2002.

CHARVET, John. The Social Problem in the Philosophy of Rousseau. Cambridge: Cambridge University Press, 1974.

COBBAN, Alfred. Rousseau and the Modern State. 2 ed. London: Archon Books, 1964.

COHEN, Joshua. Rousseau: A Free Community of Equals, Oxford: Oxford University Press, 2010.

CROCKER, Lester G. Rousseau's Social Contract: an Interpretive Essay. Cleveland: Case Western Reserve University Press, 1968.

DÉRATHÉ, Robert. Jean-Jacques Rousseau et la science politique de son temps. Paris: Vrin, 1970.

FETSCHER, Iring. Rousseaus Politische Philosophie. Neuwied: Luchterhand, 1962.

FRALIN, Richard. Rousseau and Representation: A Study of the Development of His

Concept of Political Institutions. New York: Columbia University Press, 1978.

FRALIN, Richard. The Evolution of Rousseau's View of Representative Government. Political Theory, Vol. 6, No. 4, Special Issue: Jean-Jacques Rousseau, nov., 1978, p. 517-536.

GIERKE, Otto von. Johannes Althusius und die Entwicklung der naturrechtlichen Staatstheorie. Breslau: Wilhelm Koebner, 1880.

GOYARD-FABRE, Simone. Politique et philosophie dans l'œuvre de Jean-Jacques Rousseau. Paris: PUF, 2001.

HALL, John C. Rousseau: An Interpretation of His Political Philosophy. Cambridge: Schenkman Publishing Company, 1973.

HENDEL, Charles W. Jean-Jacques Rousseau: Moralist. London: Oxford University Press, 1934.

KANT, Immanuel, AA 20: Handschriftlicher Nachlaß. Bemerkungen zu den Beobachtungen über das Gefühl des Schönen und Erhabenen. https://korpora.zim.uni-duisburg-essen.de/kant/ aa20/

, Kevin. London: Continuum, 2010.

MACHIAVELLI, Nicolò. Discorsi sopra la prima Deca di Tito Livio. Firenza: Sansoni, 1971.

MANIN, Bernard. The Principles of Representative Government. New York, NY: Cambridge University Press, 1997.

MASTERS, Roger D. The Political Philosophy of Rousseau. Princeton: Princeton University Press, 1968.

MILLER, James. Rousseau: Dreamer of Democracy. New Haven, CT: Yale University Press, 1984.

PETTIT, Philip. Republicanism: a Theory of Freedom and Government. Oxford: Oxford University Press, 1997.

PLAMENATZ, John. Oxford: Oxford University Press, 2012.

RILEY, Patrick. Will and Political Legitimacy: A Critical Exposition of Social Contract Theory in Hobbes, Locke, Rousseau, Kant, and Hegel. Cambridge, MA: Harvard University Press, 1982.

(ed.) Thinking with Rousseau: From Machiavelli to Schmitt. Cambridge: Cambridge University Press, 2017.

ROUSSEAU, Jean-Jacques. Du contrat social. [Paris]: Gallimard, 1964.

ROUSSEAU, Jean-Jacques. Projet de constitution pour la Corse. La gaya scienza, (C) avril 2012.

ROUSSEAU, Jean-Jacques. VOLUME 1. Ouvrages de politiques, in : Collection complète des oeuvres, Genève, 1780-1789, vol. 1, in-4º édition en ligne www.rousseauonline.ch, version du 7 octobre 2012. http://www.rousseauonline.ch/Text/volume-1-ouvrages-depolitique.php.

ROUSSEAU, Jean-Jacques. VOLUME 5. Emile, ou de l'éducation, tome Ilin Collection complète des oeuvres, Genève, 1780-1789, vol. 5, in- $4^{\circ}$ édition en ligne www.rousseauonline.chversion du 7 octobre 2012. .

ROUSSEAU, Jean-Jacques. VOLUME 6. Mélanges, tome premierin Collection complète des oeuvres, Genève, 1780-1789, vol. 6, in-4 $4^{\circ}$ édition en ligne www.rousseauonline.chversion du 7 octobre 2012. .

SABINE, George H. A History of Political Theory. New York: Holt, Rinehart \& Winston, 1961.

\section{Notas}

1 Lista de abreviaturas de obras de Rousseau: DI, Discours sur l'origine \& les fondements de l'inégalité parmi les hommes; CS, Du Contrat Social: ou, Principes du Droit Politique; 
CSFR, Du Contrat Social ou, Essai sur la Forme de la République; EP, Discours sur l'Economie Politique; GP, Considérations sur le Gouvernement de Pologne \& sur sa Réformation projetée; PC, Projet de Constitution pour la Corse; E, Émile ou de l'éducation; LM, Lettres Écrites de la Montagne.

2 Conforme GIERKE, p. 223; HENDEL, II, p. 169; SABINE, p. 592; CROCKER, p. 68-69. DERATHÉ, p. 279-280 e MASTERS, p. 402, consideraram que Rousseau aceitou uma versão especial do governo representativo. Enquanto FRALIN, p.517, defendeu que a sua interpretação do governo representativo, evoluiu ao longo de suas obras, mas permaneceu sempre ambivalente.

3 Posteriormente, no Livro III, cap. I do Contrato social, Rousseau introduzirá uma terceira parte da república, intermediária entre estas duas primeiras, o príncipe ou governo, possibilitando que os indivíduos assumam o papel de magistrados, que devem executar as leis, mas ele aguarda para introduzir esta terceira parte justamente por causa da "ordem de razões" que desenvolve nesta obra.

4 Calvino nasceu em Noyon, França.

5 Deve-se recordar que, até o século XVIII, o único conceito de democracia conhecido era o da Atenas dos séculos V e IV AC., onde os cidadãos deliberavam sobre as leis e aplicavam a justiça em assembleias soberanas. 